\title{
ARTICLES
}

\section{THE CHANGING LIBRARY ENVIRONMENT}

\author{
by Catherine E. Wilkins, Ed. D.
}

\begin{abstract}
This article, a summary of a recent study conducted for the author's doctorial dissertation, examines issues, trends, and relevant studies on the impact of the changing environment on the role of the librarian. Based on the enquiry conducted, she clearly sees the future role of the librarian as broadly based and focused on the utilization and evaluation of information, and as a client consultant. The librarian is seen as playing a large role in the development of information services, and as an information architect. Applying the principles developed in the frame of reference created for this study to business, research and education, will assist policy makers in making decisions about resources and training which will be needed for the development of future information resource centres. Strategic advantage due to prior knowledge will be more than ever required for organizational success.
\end{abstract}

\section{THE CHANGING LIBRARY ENVIRONMENT}

\section{Preamble}

The following article is a summary of a recent study which was conducted for my doctoral dissertation. It was an evolutionary process and it increased our understanding of the complex changes facing libraries, librarians and education. One of the contributions of this study was the creation of a frame of reference which can be used to monitor changes and forecast likely outcomes in the library environment and the role of the librarian.

\section{Introduction}

Society is rapidly approaching a turning point in its transformation to an information society and a knowledge-based economy and is characterized by major technical, economic, political, and social changes. While the transition to this new economy has been recognized for sometime, the implications are only beginning to be recognized with regard to everyday life. All sectors of our economy, both private and public, require greater access to information than ever before. Societal transformation from the industrial age to a knowledge-based information age will demand an appropriate information infrastructure to support the information-based economy. Traditionally, libraries as an institution have been one of the key support structures that hold and deliver information to the community. They are well positioned to provide equitable, costeffective, and timely information. While the institutions of the library and the librarian have always been recognized as pivotal to the support and delivery of information, their future role is not clear.

This study assessed the issues surrounding the changing library environment and, in particular, how it has influenced the role of the librarian. It forecasts a probable outcome for the library environment, including the role of the librarian in the future knowledge-based information economy. The methodology for the study is a hybrid of the survey method, 
case study research, and the Delphi method. The study was conducted in three phases. First, the literature relevant to the study was reviewed and a questionnaire was developed to gather data about those issues raised in the literature. Second, the questionnaire was distributed to participants and the results were analyzed. The third phase consisted of the development and verification of a frame of reference to synthesize the literature review and questionnaire results. The frame of reference provides a characterization for dealing with the issues in a temporal manner that can be used to forecast a probable future library environment and outline the future role of the librarian.

\section{Review Of The Literature}

The review of the literature was the first step in the process that examined current views, issues, and trends pertaining to the changing library environment and its impact on the role of the librarian. Four themes were apparent and included the conception of the library, the conception of library technology, the function of the library, and the conception of the role of the librarian.

In the literature there were many issues raised from the themes presented related to the changing nature of the library environment and the role of the librarian. These issues were generally presented according to several specific themes such as technology, the function of the library, and the role of the librarian. For example, several issues related to technology include the increasing dependence of libraries on technology, its impact on every facet of work done in the library, its concept as a physical place, the use of expert systems and software tools, the delivery of information to maximize use, the need for more concise standards for cataloguing, improved user interfaces to computer systems, and the effect of communication technology on social and cultural barriers.

Key issues related to the function of the library, which incorporate library collections and users' needs, include the change in the emphasis of library collection management, the need to standardize and verify the quality of information available over the Intermet, the status of the non-electronic library, the increasing demand for access to information, filtering and synthesizing relevant information according to users' needs, and the need to continue to develop Canada's national research and education network (CANARIE) to compete in the new economy.

Pertinent issues related to the role of the librarian include changing the role of the librarian at an operational level, the need to maintain services while controlling costs, the need to understand users' information needs and relevant business issues, the design of the library environment to meet the needs of its user community, and the definition of the future role of the librarian.

Finally, some additional issues were raised pertaining to the educational needs of the information society, and these include the restructuring of the leaming process to meet the needs of an information-based economy (especially self-directed leamers), new forms of student assessment, clarification of roles for libraries and educational institutions, the teaching of information values, using technology to develop thinking and problem-solving skills, the promotion of literacy, and, philosophically, determining who drives the change and whether it is good for us.

This study does not attempt to address all of the issues raised in the literature but will address the issues raised regarding the increasing dependence of libraries on technology, the function of the library with regard to library collections and users' needs, and the changing role of the librarian.

\section{METHODOLOGY}

\section{Introduction}

The methodology for the study conducted between September 1993 and June 1994 was a hybrid design that borrowed characteristics from the survey method, case study research methodology, and the Delphi method. The study was an evolutionary process that was conducted in three phases. First, the development of the study methodology, including the population, sample, the design, and verification of the instrumentation, is described. Second, the survey process, including the data collection and data analysis, is described. Finally, a frame of reference was constructed to synthesize the issues raised in the literature and study survey, and to provide a research-oriented approach to the possible future outcome of the role of the librarian in the changing library environment.

\section{Population and Sample}

The population and sample were designed according to the Delphi method, which uses the opinions of experts for forecasting future events. Named authorities within the library information communities were selected as the perceived experts to participate in the study. The categories of named authorities included representatives from the following populations: authors, national librarians, directors of university libraries, and directors of education libraries at faculties of education. The members of the resulting group were selected on principles of a stratified sample. However, the number of respondents available did not allow for a statistical sample deemed to represent the population. The outcome, therefore, was a group of respondents representing the various agencies and institutions but not statistically representative of the population.

\section{INSTRUMENTATION}

\section{Uniform Questionnaire}

A series of structured questions in the form of a uniform schedule were constructed as part of the instrumentation. The questions in the uniform questionnaire emerged from the issues identified in the thematic review of the literature. All questions were opened ended to stimulate and promote discussion about the global library. The questions were generally about libraries of the future - primarily what is, what ought to be, what will be and what could be. 
The content of the questionnaire solicited participants' opinions and ideas pertaining to issues relating to access to the library environment in its present forn and future direction. The following is an outline of the questions used in the questionnaire that was the focus of the study:

1. What services do you expect your libraries to be providing in the next 10 years? Please include both services that will be continued from the present and new services.

2. What impact has technology had on:

A. your library?

B. your users?

3. What are some specific user requests that you could not fill at present, but could with new technology?

4. What will your library users be like as infornation seekers in the year 2001?

5. Are the current electronic information retrieval tools easily understood by users?

6. Are the current descriptive and subjective cataloguing standards effective when translated into electronic coding for the global library?

7. A. How will the role of the library as "electronic pathway," rather than physical guardian of a collection, affect access to information? Do you in fact agree that this is where libraries are headed?

B. What variety of media will your inhouse collections include?

C. How will the library of the future provide access to information by electronic means?

8. Today there is a myriad of information sources accessible and available through global networking. What are the issues of govemance, i.e., ownership, integrity of the whole and provision of information, over the long term?

9. Once the global library of the future is established, what impact will it have on the democratic process? Will we be able to ensure equitable access gateways? Will we achieve universal access to information?

10. If we assume that there is a certain obsolescence to some information, how can the global library of the future help by restructuring information to compensate?

11. What role will the librarian as information intermediary play in the future?

\section{Data Collection}

In this study there were two parts to the data collection process. The first part utilized a structured uniform questionnaire for the collection of data via the Internet. The second part of the data collection was a feedbackprocess, in which the participants were asked to verify a framework that was constructed at the conclusion of part one and which outlined the changing library environment for three time frames, namely past, present, and future.

\section{Data Analysis}

The data collected in part one was initially analyzed from three perspectives. This included who responded and what they said, how they communicated, and what metaphors were used in their responses. The perspective of who responded and what was said included summaries of the responses that were reported by group. How they communicated refers to the mode of communication used during part one of the data collection, that is, via Intermet, facsimile, mail, voice, or any combination. In the responses, numerous metaphors were used by the respondents to "tell their story," and these were reported for each question and then analyzed for congruence and contradictions.

As the study evolved in format, the emphasis of the research questions evolved, and as a result the study was conducted in two parts to capture the focused nature of the research problem. The research problem evolved to focus on how the changing library environment influenced the role of the librarian, and the data analysis also evolved. To investigate this inquiry best, it was necessary to understand the perspective of the changing role of the librarian within changing library environment over time. A framework was created which helped to establish some baseline data about how the changing library environment has influenced the role of the librarian and to enable forecasts about the future.

The framework developed for the investigation of the research question was the Frame of Reference for the Changing Library Environment, presented as Figure 1 (Appendix A). It provided a theoretical structure to synthesize symmetrically and thereby capture the changing role of the librarian from the perspective of the past, present, and future. The data included in the construction of each frame of reference were based upon the review of the literature, a content analysis of what the respondents in phase two of the study said, and further interviews in phase three.

\section{RESULTS}

Frame of Reference for the Changing Library Environment

The frame of reference for the investigation of the research question was a symmetrical description and analysis of the library environment over time, including past, present, and future, and each time frame included the following four elements:
A. The role of the librarian
B. The library collection
C. The technologies present
D. The user's needs.

These four elements are the primary elements of the library environment and they are considered to be symbiotically related to each other.

The frame of reference provides a theoretical structure to synthesize symmetrically and thereby capture the changing role of the librarian from the perspective of the past and present and enables a projection to the future. The diagram Frame of Reference for the Changing Library Environment (Appendix A) helps to provide a focus on the theoretical structure and maintains a symmetry for each of the three time frames. Each of the time frames was described in terms of the four primary elements. A metaphor was presented to characterize the role of the librarian 
in each of the three time frames, and its intent was to capture succinctly the metaphorical nature of the changing role of the librarian in the past, present, and future, while maintaining the symmetry of the frame of reference. Once each of the three time frames was described, the changes were evident. Looking at the characteristics of each element over time, one can see that certain processes or responsibilities continue and new ones evolve or emerge. The foursymmetrical elements of the library environment are evident in each time frame and since the role of the librarian has been the main focus, it is described in greater detail according to five symmetrical subcategories. Each of the four elements are expanded in greater detail according to each time frame. The detail illustrates the changes, including additions, deletions, and expansions, to processes and responsibilities that have taken place between the three frames of reference. The use of symmetrical categories created to describe the role of the librarian in each of the three time frames facilitated the development of the transformation factors that affected the role of the librarian. Once the transformational factors between the past and present were identified, it was possible to postulate the factors affecting the transformation of the role of the librarian between the present and the future.

Based on these assumptions, a symmetrically structured role for the librarian of the future was developed. The frame of reference for the changing library environment and the detailed synthesis of each time period were verified by the study respondents.

Applying the principles of the frame of reference a likely outcome for the future library environment was forecast and is presented here in detail.

\section{Frame of Reference for the Future Library Environment}

\section{Role of the Librarian}

The conceptual metaphors that will likely describe the role of the librarian in the future are "an architect of information sources and services, and a client consultant."

Access to information: Access to information will deal with recorded information and will include multimedia and ephemeral forms, including voice, image, and holographic images. Information will be from current and archival sources from local library holdings, remote locations, and people with additional information. Information will be seamlessly accessed and transferred from anywhere to anywhere.

Collection Management: The librarian will be responsible for collection development processes, including the selection, acquisition, de-acquisition, processing, organization, storage, and preservation of information, and there will be an emphasis on the development of primary research collections. The librarian will also be responsible for providing pathways to remote information as in collection management, which will evolve to become information management, incorporating collection development and management with the provision of gateways to global information sources for current and future users.
Client Services: The focus of client services will be reference and research services, which will vary depending on type of library and the library's clientele. In the public library, direction and education will be provided to promote literacy and leisure. In the academic library, client services will require that the librarian is a subject specialist capable of scholarly research and education for its clientele. Special libraries will provide client services where the librarian will be an information specialist who will be a research team member and provide education to the client base. The information consultant will provide private research services based on the needs of the clients. In the virtual library, where virtual patrons will access the library gateways from anywhere, the librarian will provide virtual client services such as education, consultation regarding relevant information sources, and interpretation of the context of information sources.

Linkages: The degree of linkage to the institution will vary depending on the role and type of library. In general, librarians will continue to serve individuals who are part of parent institutions, and the library environment will allow for multiple linkages to outside organizations and institutions in keeping with the global information based economy.

Skills and Expertise: The skills and developed expertise in the future environment will continue to include maintaining an awareness of information sources, technology, and users' needs, which will include both local and virtual users. The librarian will need to be skilled in evaluation methods needed to evaluate information sources, information technology systems, and library services. In addition, the librarian will need knowledge of how people seek and use information, and have the ability to design and build databases and gateways to information sources and services for optimal client usage. Data analysis skills and teaching skills will also be required. The librarian will be expected to maintain a professional network to affiliated organizations and libraries for cooperative sharing of resources.

\section{Library Collections}

In the future library environment, library collections will continue to include local inhouse collections of current and archival documents, with an emphasis on primary research resources. They will be enhanced to incorporate seamless access to remote collections and information sources from anywhere to anywhere. Library information will be available in various multimedia and ephemeral forms and be aimed current and future users on a global level. Information will be easily reproduced and manipulated, which will facilitate on-site storage and remote distribution of information. Library collections will continue to be physically integrated and collocated by subject for browsing, where local and remote users will physically and electronically browse the collections on "virtual shelves" with hyper-text images, which will preserve access to information by serendipity through browsing. 


\section{Technology}

The technology in the future library environment will have several likely characteristics. Machine-readable catalogue databases will be enhanced to store multiple types of records including, bibliographic records, bibliographic and abstract records, full-text records, numeric records, image records, voice records, and holographic image records. It is likely that the numerous forms of information will be less relevant to the librarian and the user as technology will be capable of decoding information, digitizing archival materials for storage, and then re-creating information for users based on individual needs. Technology will be enhanced to provide seamless pathways to local and distributed holdings and to remote information sources. Access to information via the library catalogue will include the present access points and, in addition, access by voice and expert systems will be provided for local and remote users. Technology will be enhanced to track original and reproduced copies of documents to protect intellectual property, and the provision of the whole for posterity.

\section{Users' Needs}

In the future library environment, users' needs will have several distinct characteristics. Timeliness and relevancy will continue to be important factors and users will likely expect information on demand in multi-media formats to meet their individual needs. In the future, both inexperienced and sophisticated users will need some basic level of information literacy skills if they are to have equitable access to infornation. Specifically, they will continue to need help in defining information needs into a searchable question and then again when interpreting and evaluating the information sources. All users will require training to use information storage and retrieval systems, information access gateways, expert systems, and, ultimately, to filter through vast information sources.

The detailed synthesis of the past, present, and future frames of reference and the two sets of transformation factors, as outlined, were verified by the respondents in phase three of the study. When characterization of the frame of reference was presented to the participants during the verification process, some cosmetic changes were made, but in general participants supported its fundamental concepts.

\section{Summary of the Results}

The respondents to the survey suggested that many aspects of the library environment are changing, which they attributed largely to increasing and improving technologies. Overall, they believe that technology has improved the library environment but cautioned that policies are needed to solve several major govemance issues, such as copyright, intellectual property rights, equity of access, archives, information standards, privacy, and funding. Also stressed was that the changing library environment has many implications that are influencing the role of the librarian.

The Frame of Reference for the Changing Library Environment (Figure 1) was supported in the literature, the survey responses, and the verification process. It clearly identifies the factors that transformed and are continuing to transform the changing library environment and influencing the role of the librarian. It also provides a probable forecast for the future library environment and role of the librarian.

\section{Scenarios of the Past, Present and Future}

To illustrate how the frames of reference work, the following example will begin with a scenario of the past, describe the present, and project a likely future outcome in the changing library environment. Following the criteria of the frames of reference within the library environment, one of the functions of the role of the librarian is to facilitate access to information. To explain how the frames of reference and the transformation factors work, the scenarios will describe the process for gaining access to information in each time period and the role the librarian played in the process.

\section{The Past Scenario}

In the past, as a "custodian of books," the role of the librarian was to work with the user who came to the library to define the information need and select appropriate subject headings; search the relevant manual databases, which included the card catalogue, printed indexes and abstracts, and local union catalogues; and retrieve bibliographic references. Then the user or the librarian would go to the shelves to retrieve the relevant sources manually (primarily books, joumals, and manuscripts) from within the library's holdings. The librarian arranged for local interlibrary loans, according to the policies of the library, when relevant materials that appeared in printed indexes and union catalogues were not part of the library's collection. Some materials from remote locations may not have been available through interlibrary loan, and the user would have to go to the remote location, or manage without access to the particular materials. The materials from the library collection were available for borrowing and the materials acquired from remote location were available for use in the library only, as this was a condition of regional interlibrary loan policy between sharing libraries and institutions.

\section{The Present Scenario}

In the present library environment, as a "guardian of collections and pathway to information," the role of the librarian pertaining to access to information has more variables, depending upon the type of library and the user community. Typically, the user contacts the librarian and may come to the library, and together they define the information need and construct a search strategy, which may include subject descriptors and keywords formulated into a boolean search strategy. The librarian then recommends relevant information catalogues and databases, both local and remote, which may then be searched. The librarian may also recommend people with additional information. The user may then request to have the librarian conduct the search, or in some settings perform some of it themselves. This depends largely on the library setting and the users' skills. The results of the search will vary depending on the type of database searched, and may include 
bibliographic, bibliographic and abstract, and full-text records. The user then identifies the relevant materials that are needed from the local collection and those from remote locations. The information sources are available in multimedia or ephemeral forms. The librarian will then arrange for interlibrary loan or document procurement for remote materials, depending upon the policies of the library. The user will then retrieve the materials required from the local library collection. The materials from the local collection may be available for borrowing, or may be photocopied within the boundaries of the copyright legislation. The materials received from remote locations may be used in the library, depending on the interlibrary loan agreement, and the documents procured from remote locations are likely photocopies within the boundaries of the copyright legislation, and the user will be able to borrow these for use outside the library, depending upon the local library policies.

\section{The Future Scenario}

In the future, as an "architect of information sources and services and client consultant," the role of the librarian will evolve with the outcome pertaining to access to information being that users, working from their workstations, will be able by voice to negotiate and create a search strategy with the assistance of computer-aided expert systems. Technology will have become more user friendly, and users with access to the technology will know how to use it. Other users will contact the librarian remotely and together in an interactive mode they will construct a search strategy based on the users' information needs with the assistance of computer-aided expert systems. The search strategy will be constructed based upon the users' natural language. The expert search system will be able to translate or interpret a user's information need into an appropriate search strategy and select relevant databases, both local and remote, to be searched on a global level. The user will be able to request that the search be conducted and information sources will be will be retrieved in a seamless process transparent to the user. Once the search is complete, users will be able to select the relevant materials in a variety of forms to meet their individual needs. The librarian may be involved directly in an interactive mode here, to assist with the selection of the most relevant materials. The process of acquiring and delivering information will be seamless to the users. The information that is delivered to the user will likely be a reproduction of the original, and the original will be maintained and identified as such by the local library or institution.

Information will be available in various multimedia and ephemeral forms, e.g., voice, video, and optical, compact, and portable disks. The expert search system will track the transportation of the reproduction, and encode the original to protect it for posterity. If the reproduction has a "loan period" such as an expiry date, it will then automatically vanish upon expiry. Many of the reproduced materials will be copyrightfree and will become the property of the user. The user will still go to the library to view the document in its original form if necessary. The search process will likely happen without the direct intervention of the librarian if users have the skills and access to utilize the technology themselves.

Although the group of respondents who completed the survey and verified the frame of reference was small, their responses were thorough and thoughtful, and included reflective comments and detail that provided much data for discussion. The evolutionary nature of the study was in keeping with the Delphi technique and the verification process of phase three gave credence to the characterization of the frame of reference for the changing library environment. The findings of the study indicate, according to all respondents, that the changing library environment will continue to influence the role of the librarian. The depth and breadth of the results provided valuable information for relating the study findings to the literature.

\section{CONCLUSIONS}

The study results support certain conclusions pertaining to the changing library environment and its influence on the role of the librarian. The most significant was that the library environment will continue to be influenced by technology and users' needs, and it will become a distributed virtual library governed by global policies that will ensure access to information for its diverse community of users. The study results and the literature clearly saw the future role of the librarian as broadly based and focused on the utilization and evaluation of information, and as a client consultant. The librarian was seen as playing a larger role in the development of information services as an information architect.

Subject to the limitations of the study, the data analysis supports certain conclusions pertaining to the changing library environment and its influence on the role of the librarian. Those that can be stated about the changing library environment include:

1. Technology will play an ever increasing role in the way in which libraries operate and deliver services.

2. The library will become a virtual library that provides immediate access to current and archival information from globally distributed databases.

3. The library of the future will be govemed by new policies and regulations that ensure quality, security, and integrity of information, and that minimize the censoring of information available to its users.

4. The library of the future will be able to provide information to meet specialized needs and deliver information in multimedia form.

5. Users' demands and expectations will play a significant role in the services provided by the library of the future.

6. User skills will need to improve to be able to interact effectively in the new library environment.

Several conclusions can be drawn from the study about the future role of the librarian: 
1. The role of the librarian will evolve to one that is broadly based and focused on the utilization and evaluation of information. This role can be described as a client consultant.

2. The librarian will need to acquire and maintain new skills dealing with training, technology, and information research.

3. The role of the librarian will continue to be the persona of the place known as the library.

4. The librarian will play a larger role in the development of information databases, smart software tools, and library processes. This role can be described as an information architect.

In addition to those conclusions supported by the data analysis, I will present others that I have drawn from my own interpretation of the data and my own professional experience. The results of this study present new concepts relative to our understanding about libraries and librarians of the future and confirm some timeless constants. The library environment is experiencing rapid change, parallel with changes to our society as it evolves from the post-industrial to the information age. Pervasive factors such as changing users' needs, technology, and economic, political, and social changes have an impact on the library environment. Thoughtful observation of our environment points to a conclusion that the rate and degree of change will continue to increase for the foreseeable future.

Several timeless constants that I observed, given some support in the literature and in the results of this study", were that people still like to go to the "place" known as the library and that their perceptions of what a library is and does are primarily based upon their personal beliefs and experiences. Library users still prefer to have "the book in hand," as Rider (1989) reported, and this continues to be the greatest service of the library. Let us examine the image suggested by Rider that the book is a metaphor for the image of information regardless of form. The message in this image suggests that people want to receive information by a means that will meet their individual needs and that many expect to do this at the library.

As a reflective practitioner, one must resolve the constant turmoil that is evolving in the library environment. It requires managing tremendous change such as the forms of information available, access to information, and the delivery of information, while continuing to provide relevant services to meet users' needs. These changes are also affecting the role of the librarian. The place known as the library, with its collections of information, will not be eclipsed by the technology-dispersed library of the future. It will be a matter of establishing a balance between the local and distributed library environments to meet users' needs. One must also be cognizant of our human preference for one to one interaction as was reported by Grosser (1991). The social and emotional factors we experience and value with regard to libraries cannot be overlooked. They will mould the future library to provide a neutral environment where its users can browse, read, reflect, or imagine as they take time to transform their information into knowledge. The future library environment will have to meet the information needs as well as the emotional and social needs of its users, whether they be "virtual patrons" or those who come to browse.

The library of the future will rely heavily on technology. It will be a virtual, digital, multimedia library that provides immediate access to current and archival information and globally distributed databases; it will provide services to a diverse community of local and remote users; it will be govemed by cooperative policies and regulations to ensure equity of access to information, integrity of information, and to minimize the censorship of information; it will provide education and training for users to facilitate access to information; and it will require a highly trained professional to orchestrate and conduct it.

I perceive the role of the librarian of the future to be a balance between a client consultant and an architect of information sources and services. In this future context, access to information will be dependent upon the effectiveness of the librarian who, as an information catalyst, facilitates change and uses the information sources and technologies available to search, retrieve, evaluate, analyze, and synthesize information to provide relevant information within the context of the users' needs. The role of the librarian of the future is a blend of client consultant, interpreter, and a catalyst to the process of discovering information. As an information catalyst, the librarian of the future will play the role of interpreting users' information needs, connecting users to relevant information and to other people with additional information. As the architect of information sources and services, the librarian of the future will be a key player and provide guidance for design, building, and accessing distributed virtual digital information databases. In order to survive as key information players in the future library environment, librarians will need to broaden and intensify their skills and expertise. They will require greater technical expertise, communications and interpersonal skills, knowledge of information sources, teaching skills, and familiarity with legislation.

The Frame of Reference for the Changing Library Environment created in this study will be a useful tool for monitoring changes in the library environment and the changing role of the librarian. Applying the principles developed in the frame of reference to specific library environments, such as business, research, and education, will assist policy makers in making decisions about the kind of resources and trainingneeded to create the type of information resource centre essential in an information-based society, where strategic advantage based on knowledge is paramount to organizational success. 


\section{BIBLIOGRAPHY}

Beheshti, Jamshid. (1992). "Browsing through public access catalogues." Information Technology and Libraries, 7, 220-228.

Carpenter, J. P. (1989, May 12). Using the new technologies to create links between schools throughout the world: Colloquy on computerised school links. Strasbourg, France: Council for Cultural Cooperation, School Education Division. (ERIC Document Reproduction Service No. 318 658).

Cohen, Joel A. (1993). The electronic library in higher education: An overview and status report. Washington, DC: Georgetown University, Center for Teaching and Technology, Academic Computing Center.

Crawford, Walt. (1987). Patron access issues for online catalogues. Boston, MA: G.K. Hall.

Drenth, Hilary, et al. (1991). "Expert systems as information intermediaries." In Martha E. Williams (Ed.), Annual Review of Information Science and Technology Vol. 26 (pp. 113-154). Medford, NJ: Leamed Information.

Eisenberg, Michael B., et al. (1990). Trends and issues in library and information science 1990. Washington, DC: Office of Educational Research and Improvement. (ERIC Document Reproduction Service No. 335 061).

—_ \& Spitzer, Kathleen L. (1991). "Information technology and services in schools." In Martha E. Williams (Ed.), Annual review of information science and technology Vol. 26 (pp. 243-286). Medford, NJ: Leamed Information.

Emihovich, Catherine, \& Wagner, Walter. (1992). "Media culture/school culture." Education and Urban Society, 24, 435-439.

Fasick, Adele M. (1992). "What research tells us about children's use of information media." Canadian Library Journal, 49, 51-54.

Gifford, Bemard R. (1992a). "The learning society: Libraries without books?" Special Libraries, 83, 154-155.

(1992b). "Where is the knowledge: Knowledge management, research and pedagogy in the electronic age." Education Libraries, 16, 14-22.

Gregor, Dorothy, \& Mandel, Carol. (1991). "Cataloguing must change." Library Journal, 116, 42-47.

Grosser, Kerry. (1991). "Human networks in organizational information processing." In Martha E. Williams (Ed.), Annual Review of Information Science and Technology Vol. 26 (pp. 349-402). Medford, NJ: Leamed Information.

Grunder, Tom. (1992). "Whose Intemet is it anyway? A challenge." Online, 16, 6-10.
Hildreth, Charles R. (1987). "Beyond boolean: Designing the next generation of online catalogues." Library Trends, 35, 647-667.

Krol, E. (1992). The Whole Internet User's Guide. Sebastopol, CA: O’Reilly \& Associates.

Kuhlthau, Carol C. (1989). "Information search process: A summary of research and implications for school media programs." School Library Media Quarterly, 18, 19-24.

Mancall, Jacqueline C., Lodish, Enica K., \& Spinger, Judith. (1992). "Searching across the curriculum." Phi Delta Kappan, 73, 526-28.

Moore, Penelope A., et al. (1991). "Children as information seekers." School Library Media Quarterly, 19, 161-168.

Morris, A. (1991). "Expert systems for library and information services - A review." Information Processing \& Management, 2, 713-724.

Nelson A. Rockefeller Institute of Government. (1989). "Technology and the research environment of the future. The impact of the information science revolution on the research environment of the future." Proceedings of three seminars. Albany, NY: State Library, State University of New York. (ERIC Document Reproduction Service No. 325 080).

Neway, Julie M. (1985). Information specialist as team player in the research process. Westport, CT: Greenwood Press.

Ontario. Advisory Committee on a Telecommunications Strategy. (1992). Telecommunications Enabling Ontario's Future. The report of the Advisory Committee on a Telecommunications Strategy for the Province of Ontario to the Minister of Culture and Communications. Toronto: Ministry of Culture and Communications.

Rider, F. (1989). "The future of the research library." College and Research Libraries, 50, 49-55.

Saunders, Laverna M. (1992b). "The virtual library: Computers in libraries in Canada." Computers in Libraries, 12, 71-74.

Schuman, G. P. (1990). "Reclaiming our technological future." Library Journal, 115, 34-38.

Spaulding, F. G. (1988). "Special librarian to knowledge counsellor in the year 2006." Special Libraries, 79, 83-91.

Tillman, Hope N., \& Ladner, Sharyn J. (1992). "Special librarians and the INTERNET." Special Libraries, 83, 127-131.

Willard, Ann M., \& Morrison, Patricia. (1988). "The dynamic role of the information specialist: Two perspectives." Special Libraries, 79(4), 271-276.

Catherine E. Wilkins is the Director of the J. A. Turner Professional Library, Peel Board of Education, Mississauga, Ontario, Canada. 